\title{
Molecular genetic analysis of central nervous system germ cell tumors with comparative genomic hybridization
}

\author{
Dominik T Schneider ${ }^{1}$, Susanne Zahn ${ }^{1}$, Sonja Sievers ${ }^{1,2}$, Katayoun Alemazkour ${ }^{1}$, \\ Guido Reifenberger ${ }^{3}$, Otmar D Wiestler ${ }^{4, \dagger}$, Gabriele Calaminus ${ }^{1}$, Ulrich Göbel ${ }^{1}$ \\ and Elizabeth J Perlman ${ }^{5}$ \\ ${ }^{1}$ Clinic of Paediatric Oncology, Haematology and Immunology, Heinrich-Heine-University, Düsseldorf, \\ Germany; ${ }^{2}$ Max Planck Institute of Molecular Physiology, Dortmund, Germany; ${ }^{3}$ Department of \\ Neuropathology, Heinrich-Heine-University, Düsseldorf, Germany; ${ }^{4}$ German Brain Tumor Reference \\ Center Institute of Neuropathology, University of Bonn, Bonn, Germany and ${ }^{5}$ Department of \\ Pathology, Children's Memorial Hospital, Chicago, IL, USA
}

\begin{abstract}
The limited information available to date regarding the genetic alterations in germ cell tumors of the central nervous system has raised concerns about their biologic relationship to other germ cell tumor entities. We investigated fresh-frozen or archival tumor samples from 19 patients with central nervous system germ cell tumors (CNS-GCTs), including seven germinomas, eight malignant nongerminomatous germ cell tumors and four teratomas, using chromosomal comparative genomic hybridization to determine recurrent chromosomal imbalances. All 15 malignant CNS-GCTs and two of four teratomas showed multiple chromosomal imbalances. Chromosomal gains (median: 4 gains/tumor, range: 0-9 gains/tumor) were observed more frequently than losses (median: 1.6 losses/tumor, range: 0-6 losses/tumor). Gain of 12p, which is considered characteristic for germ cell tumors of the adult testis, was detected in 11 of 19 tumors and 10 of 15 malignant CNS-GCTs. In one tumor, gain of $12 p$ was confined to an amplicon at 12p12, corresponding to the commonly amplified region on $12 p$. Other common gains were found on chromosome arms $1 q$ and $8 q(n=9$, each). Among the chromosomal losses, parts of chromosome $11(n=5), 18(n=4)$, and $13(n=3)$ were deleted most frequently. Notably, we observed no difference in the genetic profiles of germinomatous and nongerminomatous CNS-GCTs; however, the average number of imbalances was higher in the latter group. A meta-analysis comparing 116 malignant gonadal and extragonadal germ cell tumors revealed that the genomic alterations in CNS-GCTs are virtually indistinguishable from those found in their gonadal or other extragonadal counterparts of the corresponding age group. These data strongly argue in favor of common pathogenetic mechanisms in gonadal and extragonadal germ cell tumors.
\end{abstract}

Modern Pathology (2006) 19, 864-873. doi:10.1038/modpathol.3800607; published online 7 April 2006

Keywords: germ cell tumor; central nervous system; extragonadal; chromosomal profile; isochromosome 12p; meta-analysis

During childhood and adolescence, the majority of germ cell tumors arise outside of the gonads, and beyond early childhood, the central nervous system and the mediastinum constitute the most frequent sites of extragonadal germ cell tumors. ${ }^{1}$ The vast

Correspondence: Dr DT Schneider, MD, Clinic of Pediatric Oncology, Hematology and Immunology, Heinrich-Heine-University, Medical Center, Moorenstr. 5, Düsseldorf 40225, Germany.

E-mail: dominik.schneider@uni-duesseldorf.de

${ }^{\dagger}$ Current address: German Cancer Research Center (DKFZ), Heidelberg

Received 13 December 2005; revised and accepted 13 March 2006; published online 7 April 2006 majority of central nervous system germ cell tumors (CNS-GCTs) develop in the pineal gland or the suprasellar region, and approximately $10 \%$ of all CNS-GCTs present as bifocal tumors., ${ }^{2,3}$ The extragonadal appearance of germ cell tumors is likely related to errors in germ cell migration during early embryonal development. Accordingly, imprinting studies of gonadal and extragonadal germ cell tumors show loss of the methylation imprint at imprinting control regions, correlating with the methylation status within early stages of primordial germ cell development. ${ }^{4-6}$ However, the molecular mechanisms that interfere with normal homing of germ cells to the gonadal ridge and that allow for a 
sustained survival of germ cells in an extragonadal environment remain unclear. Furthermore, the molecular mechanisms of the apparent tropism to the pineal gland and suprasellar region in particular have to be elucidated.

Morphologically, gonadal and extragonadal germ cell tumors are virtually indistinguishable. Apart from spermatocytic seminomas, which may develop in the testis of elderly patients, all histologic entities of germ cell tumors may also arise in the central nervous system. Among malignant germ cell tumors, germinomas are distinguished from nongerminomatous germ cell tumors, which include embryonal carcinoma, yolk sac tumor and choriocarcinoma. In addition, teratomas can be distinguished as a distinct group with a histologically benign appearance. These may include completely differentiated organoid (mature teratoma) or immature structures, the latter resembling immature steps of embryonal and fetal organ development. Characteristically, malignant nongerminomatous germ cell tumors present as tumors with composite histology that include different histologic subentities. It is generally assumed that this phenomenon is related to the cell of origin, the totipotent primordial germ cell, which may differentiate along many different pathways.

Among all germ cell tumors, malignant testicular germ cell tumors of young adults constitute the most intensively studied entity. These are characterized by a specific cytogenetic aberration, the isochromosome 12p (i (12p)), which is considered pathognomonic and can be detected in about $80 \%$ of malignant testicular germ cell tumors. ${ }^{7}$ In the remaining tumors, gain of chromosomal material of $12 \mathrm{p}$ is related to either marker chromosomes or homogeneously staining regions that contain chromosomal material derived from chromosomal band 12p11.2-12.1. ${ }^{8,9}$ Additional chromosomal imbalances have also been reported in testicular germ cell tumors. However, these are less frequent and less consistent as compared to gain of $12 p .^{10-12}$ Notably, testicular germ cell tumors that arise during infancy and childhood show a divergent genetic profile that is characterized by loss of $1 \mathrm{p}$ and $6 \mathrm{q}$, and gain of $1 \mathrm{q}$ and 20 , while gain of $12 \mathrm{p} 11-12$ is not detectable. ${ }^{13-16}$ In extragonadal germ cell tumors, similar age-dependent cytogenetic and moleculargenetic patterns have been identified. ${ }^{13,17}$

There are only limited data regarding cytogenetic and molecular genetic patterns of intracranial germ cell tumors. The largest genetic study published to date includes 15 pineal germ cell tumors analyzed with comparative genomic hybridization (CGH). In this study, only a minority of germinomas showed gain of $12 p \cdot{ }^{18}$ Others detected gain of $12 p$ at varying frequencies. ${ }^{19-23}$ Therefore, several authors concluded that gain of $12 \mathrm{p}$, which constitutes the biologic hallmark of germ cell tumors in adolescents and adults, does not play a major role in the biology of CNS-GCTs, thus distinguishing these from their counterparts at gonadal or other extragonadal sites, such as the mediastinum. ${ }^{18,23}$ Of note, the genetic profiles of pineal germ cell tumors were different from pineal parenchymal tumors, which frequently showed gain of $12 \mathrm{q}$ and $22 .^{24}$

Considering these conflicting data, we have performed chromosomal CGH analysis of 19 tumors from representative histologic groups in order to define characteristic patterns of chromosomal imbalances in CNS-GCTs. In addition, we compared the CGH profiles of CNS-GCTs to those of 101 malignant germ cell tumors from gonadal and different extragonadal sites, including tumors of different age groups and all histologic entities.

\section{Materials and methods}

\section{Patients}

Fresh-frozen tumor tissue $(n=14)$ or formalin-fixed and paraffin-embedded archival tumor tissue $(n=6)$ was obtained from the germ cell tumor bank of the Pediatric Oncology Group, the German Brain Tumor Reference Center in Bonn, Germany, the Department of Neuropathology in Düsseldorf, Germany, and the German Children's Tumor Registry in Kiel. In one case, both fresh frozen and paraffin embedded tissue was available for analysis, and both experiments yielded identical profiles. All tumors were classified according to the WHO classification of brain tumors and germ cell tumors. ${ }^{25,26}$ Hematoxylin-Eosin stained sections were evaluated prior to DNA extraction. Only those tumor samples that showed more than $70 \%$ viable tumor cells were analyzed. Germinomas with pronounced lymphocytic infiltration comprising greater than $30 \%$ of the specimen cellularity were excluded. A brain metastasis of a testicular nonseminomatous germ cell tumor was included for comparison to primary CNS-GCTs. None of the patients had a history of a previous, synchronous or metachronous testicular, ovarian or extracranial extragonadal germ cell tumor. The study was reviewed and approved by the Local Ethics Committee of the Heinrich-Heine University, Düsseldorf, Germany, and the Joint Committee on Clinical Investigations of the Johns-Hopkins Medical Institutions, Baltimore, MD, USA.

\section{DNA Extraction from Fresh-Frozen Tissue}

DNA was salt-extracted from twenty $5 \mu \mathrm{m}$ sections after sodium dodecyl sulfate (SDS)/proteinase $\mathrm{K}$ (GibcoBRL, Rockville, MD, USA) digestion for $24 \mathrm{~h}$, and purified with phenol-chloroform-isoamyl alcohol extraction followed by ethanol precipitation using standard protocols. ${ }^{27}$ Alternatively, DNA was extracted with the DNeasy Tissue Kit (Qiagen, Hilden, Germany), according to the manufacturer's instructions. Reference DNA was extracted from normal male lymphocytes. 


\section{DNA Extraction from Archival Tissue}

Five $10 \mu \mathrm{m}$ sections were deparaffinized with xylene and rehydrated through an alcohol series. For tumor dissection, five to $1010-\mu \mathrm{m}$ sections on glass slides were manually dissected after deparaffinization with a razor blade using a stained section as a guide. The tissue was incubated at $55^{\circ} \mathrm{C}$ for $72 \mathrm{~h}$ with SDS/proteinase K $(1.5 \mathrm{mg} / \mathrm{ml}$, new enzyme added after 24 and $48 \mathrm{~h}){ }^{28}$ DNA was extracted according to the phenol-choloform-isoamyl alcohol $\operatorname{method}^{27}$ and ethanol-precipitated.

\section{Labeling of Tumor and Reference DNA}

Prior to labeling, the presence of high-molecular weight DNA and absence of overwhelming DNA degradation (in archival tissues) were confirmed by $1 \%$ agarose gel electrophoresis, and the amount of DNA was determined with UV spectroscopy. Tumor and reference DNA ( $2 \mu \mathrm{g}$ ) were directly labeled with Spectrum-Green- and Spectrum-Red-dUTP (Vysis, Downers Grove, IL, USA) using nick translation, as previously described. ${ }^{14,17,29}$ The amount of DNase and DNA-Polymerase (GibcoBRL) and the reaction time were carefully adjusted in order to obtain labeled DNA fragment lengths of 500-2000 base pairs on a $1 \%$ agarose gel.

\section{Comparative Genomic Hybridization}

In total, $500 \mathrm{ng}$ of labeled tumor and reference DNA were ethanol coprecipitated with $20 \mu \mathrm{g}$ of Cot-1 DNA (GibcoBRL). The precipitate was resuspended in hybridization buffer containing $50 \%$ formamide, $2 \times$ SSC, and $10 \%$ dextran sulfate. The probe was denatured at $75^{\circ} \mathrm{C}$ for $10 \mathrm{~min}$ and partially reannealed at $37^{\circ} \mathrm{C}$ for $30 \mathrm{~min}$. The probe was hybridized at $37^{\circ} \mathrm{C}$ for 3 days to methotrexatesynchronized male metaphase cells that previously had been aged for 5 days, stored at $-20^{\circ} \mathrm{C}$, washed in $2 \times$ SSC, and denatured at $70^{\circ} \mathrm{C}$ for $2 \mathrm{~min}$ in $70 \%$ formamide, $2 \times$ SSC, $\mathrm{pH}$ 7.0. Posthybridization washes were performed for $5 \mathrm{~min}$ each in $2 \times$ SSC at $70^{\circ} \mathrm{C}, 37^{\circ} \mathrm{C}$, and in water at room temperature. The chromosomes were counterstained with $0.1 \mu \mathrm{g} / \mathrm{ml}$ 4'6/diamidino-2-phenylindole-2HCl (DAPI) in Antifade (Oncor, Gaithersburg, MD, USA). The experimental protocol has been validated using control samples that have been characterized by conventional cytogenetic analysis.

\section{Microscopic Analysis}

Gray-level images were aquired for each fluorescent dye with a charge-coupled device camera on a Zeiss Axioscope epifluorescence microscope, using the Applied Imaging Corporations's dedicated Cytovision soft- and hardware for 'high-resolution CGH' (according to the protected designation by
Cytovision Inc., Santa Clara, CA, USA). ${ }^{30,31}$ The chromosomes of at least 15 metaphase cells were identified using reverse DAPI banding. The background fluorescence was subtracted, and the green:red ratio of each entire metaphase was normalized to 1.0. According to the designated high-resolution modus for CGH analysis, average fluorescence ratios and 95\% confidence intervals were calculated from at least 12 representative chromosomes and compared to dynamic standard reference intervals, ${ }^{32}$ thus increasing the sensitivity and spatial resolution of chromosomal CGH to approximately $5 \mathrm{MB}^{33}$

\section{Results}

Fourteen tumors were from male and five tumors from female patients. Age at diagnosis ranged from a neonate to 25 years, with a median of 11.5 years. This distribution is in accordance with the general epidemiologic pattern of CNS-GCTs, indicating that this panel of CNS-GCTs constitutes a representative group. ${ }^{1}$ Among 18 patients with complete clinical data, pineal tumors were most frequent $(n=11)$, followed by the suprasellar region $(n=5)$ and the spine $(n=2)$. In a 3 -year-old child (Table 1, patient no. 12), a ventricular recurrence of a primarily suprasellar tumor was analyzed. Nine patients were prospectively enrolled onto the German MAKEI (Maligne Keimzelltumoren) 89 or SIOP CNS GCT 96 protocol, allowing for analysis of clinical follow-up data. The patient with tumor recurrence died as a result of tumor progression, whereas the others are in continuous remission. Table 1 summarizes the documented clinical and pathologic data in relation to the chromosomal gains and losses detected by CGH analysis.

Four patients presented with pure mature $(n=1)$ or immature $(n=3)$ teratomas, whereas all other patients suffered from malignant germ cell tumors. Seven patients had germinomas, which showed additional teratomatous elements in two patients. Eight patients were diagnosed with malignant nongerminomatous germ cell tumors. In these tumors, yolk sac tumor was the most common histologic type, followed by embryonal carcinoma and teratoma, while choriocarcinoma was detected in one patient only.

Of 19 analyzed tumors, 17 showed chromosomal imbalances (Figure 1). In general, chromosomal gains (mean: 4 gains/tumor, range: 0-9 gains/tumor) were more frequent than losses (mean: 1.6 losses/ tumor, range: 0-6 losses/tumor). The most frequent chromosomal imbalance, gain of $12 p$, was detected in 11 of 19 tumors and 10 of 15 malignant CNSGCTs. In two of these tumors, the whole chromosome 12 was gained, with one of these two tumors showing a high level gain of 12p. Notably, in one germinoma, gain of $12 \mathrm{p}$ was limited to the chromosomal band 12p12 (Figure 2). Gain of 12p was absent in tumors of the three patients who were younger than 8 years of age. 
Table 1 Summary of the clinical, pathologic and genetic data of the 19 patients with CNS-GCTs, sorted by histology and age

\begin{tabular}{|c|c|c|c|c|c|c|c|c|}
\hline \# & Tissue & Age & Sex & Site & Histology & Status & Gains & Losses \\
\hline 1 & FFT & Neonate & $\mathrm{F}$ & Spinal cord & MT & NED & None & None \\
\hline 2 & FFT & $6 y$ & $\mathrm{M}$ & Pineal gland & IT & NED & $1 q, 8,17 q, X$ & 20 \\
\hline 3 & FFT+FFPET & $8 \mathrm{y}$ & $\mathrm{M}$ & Pineal gland & IT & NED & $1 \mathrm{q}, 8,12 \mathrm{p}, \mathrm{X}$ & $9 q, 11,18$ \\
\hline 4 & FFT & $20 \mathrm{y}$ & $\mathrm{M}$ & Pineal gland & IT & ND & None & None \\
\hline 5 & FFPET & $10 \mathrm{y}$ & $\mathrm{F}$ & Pineal gland & GER, TER & NED & $1 \mathrm{q}, 8,21$ & - \\
\hline 6 & FFPET & $11 \mathrm{y}$ & $\mathrm{M}$ & Pineal gland & GER, TER & NED & $12 p, 17 q$ & - \\
\hline 7 & FFPET & $12 \mathrm{y}$ & $\mathrm{M}$ & Pineal gland & GER & ND & $1,2,8,10,12$ & $4,13 q, 22 q$ \\
\hline 8 & FFPET & $14 \mathrm{y}$ & $\mathrm{M}$ & Pineal gland & GER & NED & $\begin{array}{l}\text { 1q21-q24, 7q22-qter, } \\
\text { amp12p12, 17q24- } \\
\text { qter, } 21,22\end{array}$ & $\mathrm{Y}$ \\
\hline 9 & FFT & $15 \mathrm{y}$ & $\mathrm{F}$ & Suprasellar region & GER & ND & $8 q 11-q 21$ & - \\
\hline 10 & FFPET & $25 \mathrm{y}$ & $\mathrm{M}$ & Suprasellar region & GER & NED & $7,12 p$ & 13 \\
\hline 11 & FFPET & Adult & $\mathrm{F}$ & Pineal gland & GER & ND & $3 p, 12 p$ & $1 p, 6,11$ \\
\hline 12 & FFT & $3 y$ & $\mathrm{M}$ & Relapse (3rd ventr.) & EC, YST & DOD & $\begin{array}{l}\text { 1p21-qter, 2pter-2q22, } \\
\text { 2q34-qter, } 3\end{array}$ & 11q24-qter, 20q \\
\hline 13 & FFPET & $9 y$ & $\mathrm{M}$ & Pineal gland & IT, YST & NED & $\begin{array}{l}1 \mathrm{q}, 5 \mathrm{q}, 8,10 \mathrm{q} 22-\mathrm{q} 23 \\
12 \mathrm{p}, 16 \mathrm{q} 23-\mathrm{qter}, 22\end{array}$ & 11q14-q22, 18, Y \\
\hline 14 & FFPET & $10 y$ & $\mathrm{M}$ & Pineal gland & IT, YST & NED & $3,12 p, 14,18,21$ & - \\
\hline 15 & FFPET & $11 \mathrm{y}$ & $\mathrm{M}$ & Pineal gland & YST, EC, CHC & NED & $\begin{array}{l}\text { 2q32-qter, 8, 12, } \\
\text { amp12p, 14, 21, 22, X, } \\
\text { Y }\end{array}$ & $4,9 p, 10,11$ \\
\hline 16 & FFPET & $13 \mathrm{y}$ & $\mathrm{F}$ & Suprasellar region & YST & ND & $\begin{array}{l}1 \mathrm{q} 21-\mathrm{q} 32,2 \mathrm{p} 16-\mathrm{p} 22 \\
3 \mathrm{p}, 8,10,12 \mathrm{p}, 17 \mathrm{q} \\
20 \mathrm{q}, 21\end{array}$ & - \\
\hline 17 & FFPET & $17 \mathrm{y}$ & $\mathrm{M}$ & Suprasellar region & EC, TER & ND & $\mathrm{X}, \mathrm{Y}$ & $\begin{array}{l}\text { 3p13-p14, 5q32-qter, } \\
\text { 8q24-qter. 10q25-qter, } \\
\text { 13,18q }\end{array}$ \\
\hline 18 & FFPET & $20 y$ & $\mathrm{M}$ & Spinal cord & EC, YST & ND & $1 q, 5$ & - \\
\hline 19 & FFPET & $20 \mathrm{y}$ & $\mathrm{M}$ & Pineal gland & YST & NED & $\begin{array}{l}2,7,8 q, 12 p, 14,18 p \\
21, X, Y\end{array}$ & 8p21-pter, 15, 18q \\
\hline
\end{tabular}

FFT, fresh frozen tissue; FFPET, formalin fixed and paraffin embedded tissue; y, years; M, male; F, female; ND, no data; MT, mature teratoma; IT, immature teratoma; GER, germinoma; EC, embryonal carcinoma; YST, yolk sac tumor; CHC, choriocarcinoma; MGCT, mixed malignant germ cell tumor; NED, no evidence of disease; DOD, death of disease.

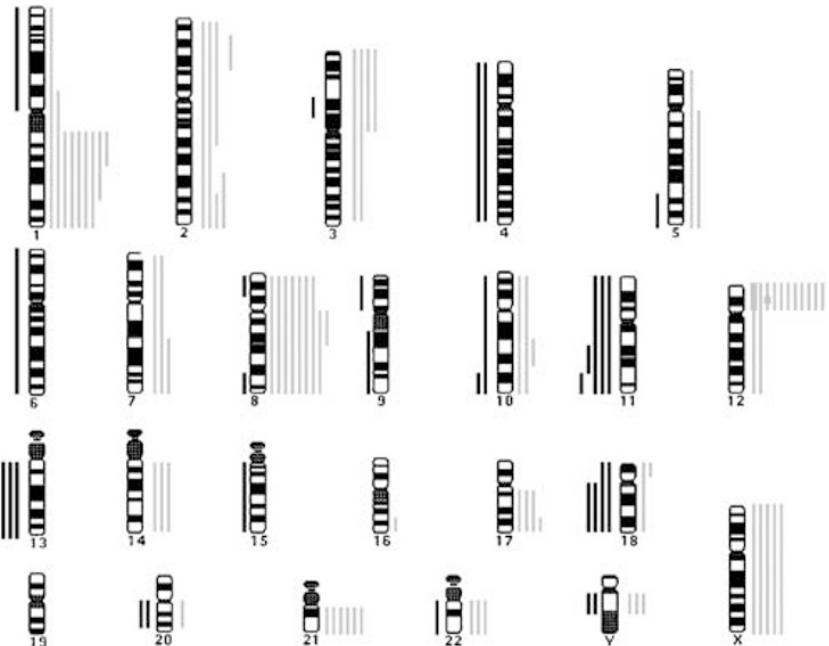

Figure 1 High-resolution CGH analysis of 19 CNS-GCTs: Each line to the right or left side of a chromosome represents a region gained or lost, respectively. Chromosomal amplifications (>1.5:1 ratio) are indicated as thick bars.

The second most common chromosomal gains were found at $1 \mathrm{q}$, with a region of overlap mapping to 1q21-q24, and chromosome 8 , with a commonly gained region at 8q11-q21. In six patients, chromosome 21 was gained, and five tumors showed gain of
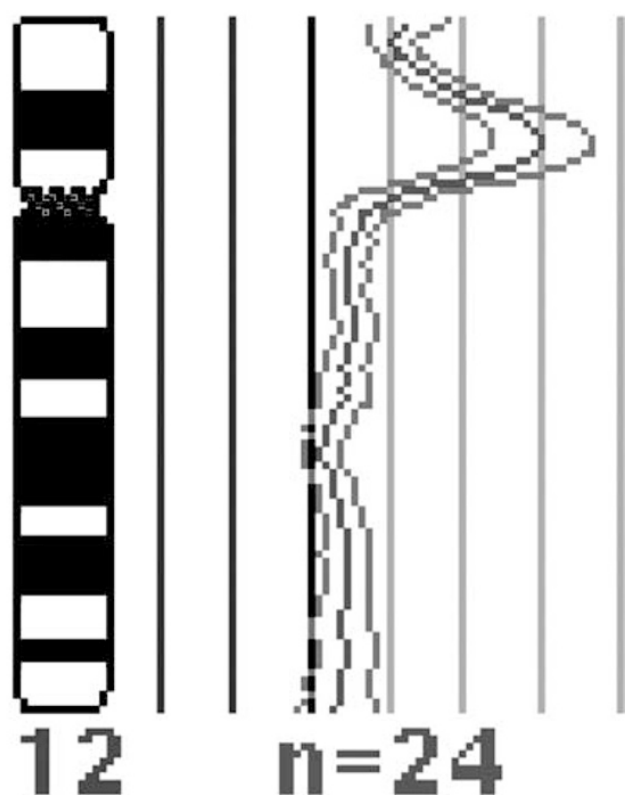

Figure 2 CGH profile of a pineal germinoma showing a circumscribed high-level amplification restricted to chromosomal band $12 \mathrm{p} 12$.

the $\mathrm{X}$ chromosome. Due to restricted tumor material and lack of normal reference tissue, no analysis defining the constitutional sex chromosomal status 
could be performed. Chromosome arms 11q and 18q as well as chromosome 13 were most frequently affected by losses of genetic material. The only tumors with balanced CGH profiles were two pure teratomas, while all malignant germ cell tumors showed chromosomal imbalances. However, the CGH profile of the two imbalanced teratomas resembled those found in malignant CNS-GCTs. Among malignant germ cell tumors, chromosomal imbalances were more frequent in nongerminomatous germ cell tumors (mean: 8.1 imbalances/tumor) than in germinomas (mean: 4.1 imbalances/tumor, Student's $t$-test, $P=0.03$ ). Particularly, chromosomal gains were more frequently detected in nongerminomatous germ cell tumors (mean: 5.9 gains/tumor) than in germinomas (mean: 3 gains/tumor, $P=0.045$ ), whereas chromosomal losses were found at comparable frequencies (mean: 2.3 vs 1.1 losses/ tumor, $P=0.27$ ).

Otherwise, no significant differences were detected when specific imbalances were compared to the different malignant histologic types. We also did not observe a significant correlation between a specific chromosomal imbalance and patient gender, tumor site or clinical outcome. Last, there was no significant correlation between the tissue type (fresh frozen or paraffin embedded) and chromosomal profiles detected with CGH.

\section{Meta-Analysis of Gonadal and Extragonadal Germ Cell Tumors}

We compared the chromosomal patterns observed in the 15 malignant CNS-GCTs of this series to those published in other major CGH studies of malignant gonadal and extragonadal germ cell tumors, in which the chromosomal profiles of individual tumors were provided, sorted by age and tumor site $\left({ }^{14,17,18,29,34}\right.$ plus 16 unpublished tumors). Other studies, in which the CGH profile cannot be attributed to individual tumors, were excluded (eg Korn et $a l^{11}$ and Mostert et $a l^{34}$ ). In total, 116 malignant germ cell tumors were included in this meta-analysis.

Similar to the study of Chibon et $a{ }^{35},{ }^{35}$ we divided the genome into 100 datapoints resulting in chromosomal segments of approximately 30-40 Megabases. Since most of the studies included did not specifically indicate chromosomal amplification, we only designated chromosomal gain as +1 and loss as -1 , while balanced regions were counted as 0 . In Figure 3, all chromosomal gains are illustrated as green bars, and losses as red bars, respectively.

This comparison revealed no detectable difference between seminomas or malignant nonseminomatous germ cell tumors. Instead, significant differences according to site and age are obvious. Loss of $1 \mathrm{p}$ is most frequent in sacrococcygeal and mediastinal germ cell tumors of infancy and childhood $(P<0.01)$, while gain of $1 \mathrm{q}$ can be found in both age groups. Loss of $6 q$ is virtually exclusive to malignant child- hood germ cell tumors $(P<0.001)$, irrespective of site. Moreover, gain of $20 \mathrm{q}$ represents a distinctive imbalance of childhood germ cell tumors $(P<0.001)$. In contrast, gain of $12 \mathrm{p}$ represents the most important marker of both gonadal and extragonadal malignant germ cell tumors of adolescent and adult patients $(P<0.001)$, but is only exceptionally found in children. In addition, gain of $8 / 8 \mathrm{q}$ is also common in this age group $(P<0.01)$. Lastly, tumors arising in adolescents and adults are characterized by more frequent gain of $7 \mathrm{q}, 21 \mathrm{q}$ and loss of $13(P<0.001)$, while gain of $3 p$ is more commonly observed in pediatric tumors $/(P<0.05)$. Taken together, this meta-analysis of 116 germ cell tumors clearly demonstrates the reproducibility of patterns detected by CGH across different laboratories.

Last, a specific comparison of the 34 CNS-GCTs analyzed by Rickert et al and our group with 36 testicular germ cell tumors was performed (Figure 4). This analysis included 18 children younger than 10 years. This analysis indicates that with regard to chromosomal imbalances detectable with CGH, there are no apparent differences according to site. The only detectable difference appears to be a higher percentage of gain of chromosome 8 in CNS-GCTs $(P<0.05)$; however, this difference is not detectable, if age is use as a stratum for comparison, indicating that the chromosomal constitution of testicular and CNS-GCTs is identical.

\section{Discussion}

The last 25 years have been characterized by a significant breakthrough in the treatment of malignant germ cell tumors, which can mainly be attributed to the introduction of cisplatin-based chemotherapy and the optimization of multidisciplinary therapeutic strategies. ${ }^{36}$ Recently, this success has been translated to the treatment of CNS-germinomas and, to a lesser extent, to nongerminomatous germ cell tumors. ${ }^{2,37-41}$ To a certain degree, the less favorable prognosis of CNS-GCTs that secrete alpha fetoprotein or human chorionic gonadotrophin (embryonal carcinoma, yolk sac tumor, choriocarcinoma) compared to secreting germ cell tumor at other sites might be related to anatomic problems that interfere with surgical resection. Nevertheless, it remains possible that specific biologic aspects of CNS-GCTs may additionally contribute to the poorer prognosis compared to malignant germ cell tumors at other sites.

In general, it can be assumed that lessons learned in testicular germ cell tumors might also be transferred to CNS-GCTs. This assumption is supported by imprinting studies implicating a common precursor cell for both gonadal and extragonadal germ cell tumors. ${ }^{5,6}$ However, there are several lines of evidence that suggest certain biologic differences between central nervous system and non-CNS-GCTs. Testicular germ cell tumors show a characteristic 


\section{Chromosome}

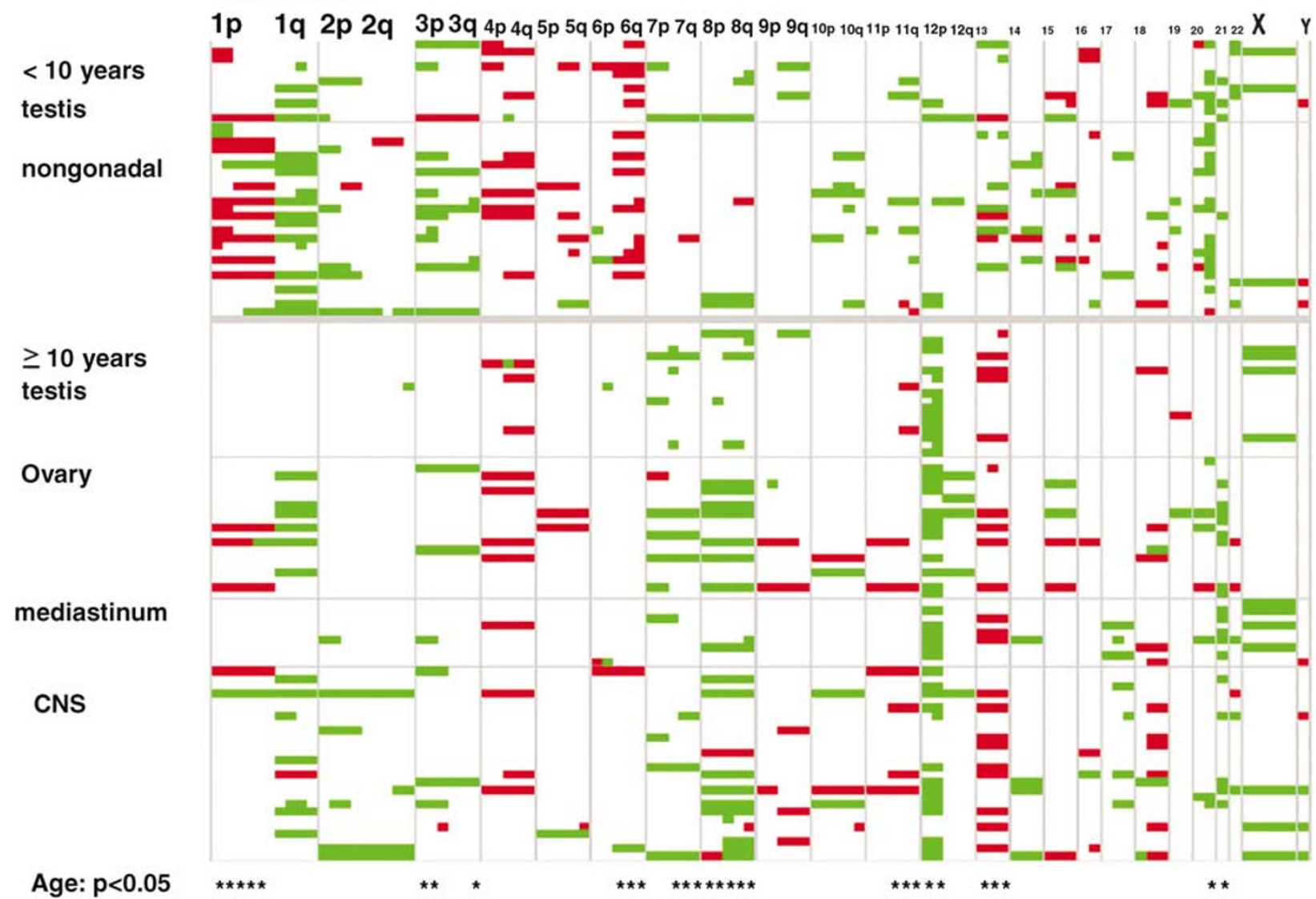

Figure 3 Meta-analysis of 116 malignant gonadal and extragonadal GCTs, separated by age and sorted by site ${ }^{14,17,18,29,34}$ (including this series and 16 unpublished tumors). Each line represents 100 chromosomal data points of a single tumor, with chromosomal gains illustrated as green bars and losses as red bars, respectively. At the bottom, chromosomal regions showing statistically significant differences that correlated with age are indicated by an asterix.

association with a preinvasive carcinoma in situ, the testicular intratubular neoplasia. ${ }^{7,31,42}$ No such in situ lesion has been seen in the brain of patients with CNS-GCT. Furthermore, it has been demonstrated that certain histologic types express markers associated with distinct maturational stages of germ cell development, which presumably are dependent on a specific gonadal environment. ${ }^{7,43-45}$ Lastly, there are some data suggesting that the chromosomal marker characteristic of testicular germ cell tumors, the isochromosome $12 p$, plays only a minor role in CNS-GCTs. ${ }^{18,22}$ As a consequence, it must be debated whether the information generated in the more frequent (and more easily assessable) testicular germ cell tumors can indeed be transferred to CNS-GCTs without scrutiny. This concern relates not only to our general understanding of CNS-GCT biology but also to the development of future therapeutic strategies.

In this context, the meta-analysis of germ cell tumors of the different clinical and histologic groups (Figures 3 and 4) provides important information. While age-dependent differences become clearly apparent, there is no obvious correlation with either site or histologic subtype of malignant germ cell tumor. ${ }^{13,14,46}$ In particular, our meta-analysis unequivocally indicates that there is no apparent difference in the chromosomal constitution of testicular and CNS-GCTs (Figure 4). In accordance with the observation that the vast majority of CNS-germ cell tumors develop in adolescents and adults, ${ }^{1}$ CNSGCTs also display CGH profiles characteristic of malignant germ cell tumors of this age group. In fact, gain of $12 \mathrm{p}$, which in most cases is related to an isochromosome $12 \mathrm{p}$, constitutes the most frequent chromosomal imbalance in our series of CNS-GCT. Furthermore, the additional chromosomal imbalances such as gain of $1 \mathrm{q}$ or 8 also occur at comparable frequencies as in other gonadal and nongonadal germ cell tumors of adults (Figures 3 and 4). Although CNS-GCTs show no bimodal age distribution as testicular or mediastinal germ cell tumors, ${ }^{1}$ our analysis suggests that also in the CNS, germ cell tumors of infancy and early childhood are genetically distinct from those of adolescence and adulthood, as indicated by the analysis of patients 1 and 12, which show profiles characteristic of teratoma and malignant germ cell tumors of 


\section{chromosome}

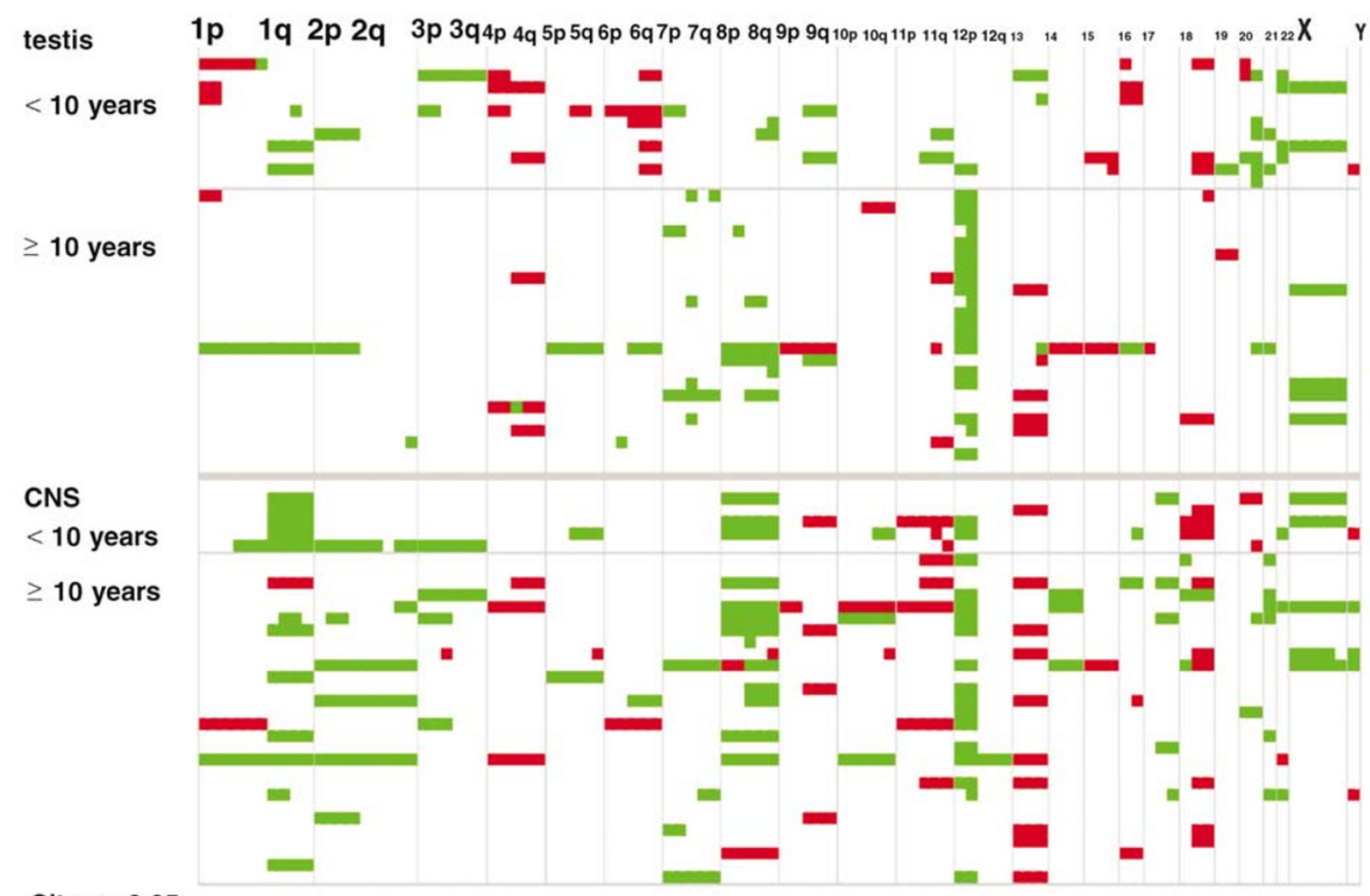

Site: $\mathrm{p}<0.05$

Figure 4 Meta-analysis of 36 testicular and 34 CNS-GCTs, separated by site and sorted by age ${ }^{15,18,34}$ (including this series and eight unpublished tumors). Each line represents 100 chromosomal data points of a single tumor, with chromosomal gains illustrated as green bars and losses as red bars, respectively. As indicated at the bottom, no chromosomal regions showed statistically significant differences correlated with site.

childhood. ${ }^{47}$ However, in the patients 2,3 and 13 , who were 6,8 and 9 years old, profiles characteristic of adolescent patients have been found. Therefore, in contrast to other sites such as the mediastinum, an age cutoff somewhat younger than 10 years might be more appropriate for CNS-GCTs, indicating for modulating local environmental factors. Nevertheless, our observation and our meta-analysis substantiate the notion that age and not site constitutes the primary distinguishing parameter.

In other extragonadal germ cell tumors (in particular mediastinal germ cell tumors), there is a significant association with constitutional Klinefelter syndrome that distinguishes these tumors from testicular germ cell tumors, for which this association is not seen. ${ }^{48,49}$ Furthermore, there have been single reports of CNS-GCTs in the presence of Klinefelter syndrome. ${ }^{50-52}$ In our series of patients, we have no clinical data indicating constitutional Klinefelter syndrome. A previous FISH analysis of six suprasellar teratomas (age 2-25 years) revealed a high frequency of sex chromosomal abnormalities, with a normal constitutional karyotype in one analyzed patient. ${ }^{53}$ In accordance to this study, both teratomas with chromosomal imbalances and three malignant nongerminomatous germ cell tumors showed gains of the X chromosome. Unfortunately, we did not have access to extratumoral tissue allowing for an analysis of the constitutional karyotype.

\section{The Role of Gain of $12 p$ in CNS-GCTs}

The question has been raised whether those CNSGCTs that lack gain of $12 p$ constitute a different biologic subtype. ${ }^{18}$ In contrast to our series, in which five of six germinomas displayed gain of $12 p$, Rickert et al found gain of $12 \mathrm{p}$ in only one out of eight central nervous system germinomas. This statistically significant difference $\left(\chi^{2}\right.$-test, $\left.P=0.02\right)$ could probably be related to methodical differences such as sample selection. Germinomas often show a pronounced lymphocytic infiltration that could significantly dilute the tumor DNA content, and therefore reduce the ability to detect chromosomal imbalances. In accordance with this hypothesis, Rickert et al detected no chromosomal imbalances in two of eight germinomas, whereas in our series, all malignant tumors showed genomic alterations. Furthermore, it might be argued whether the high-resolution CGH algorithm might additionally increase the hetero- 
geneity tolerance as it has been postulated for array CGH. ${ }^{54}$ In this context, it has to be noted that although the spatial resolution of chromosomal CGH is limited, even with array CGH approaches no discrepant or additional frequently recurrent imbalances have been detected in extracranial germ cell tumors ${ }^{16}$ or CNS-GCTs (Chin C Lau, oral presentation on the Second International Symposium in CNS-GCTs in Los Angeles, November $2005^{55}$ ).

Furthermore, other issues such as a patient selection bias must also be considered. First, the three youngest patients included in this series (and the youngest patient of the series published by Rickert et al) do not show gain of $12 \mathrm{p}$ but a CGH profile comparable to that of testicular, sacrococcygeal or mediastinal CGH at this age with imbalances of chromosome 1 and gain of $1 \mathrm{q}$ or $20 \mathrm{q}$ in malignant germ cell tumors (Figures 1 and 3). Second, three of the tumors that lacked gain of $12 p$ are teratomas. Characteristically, the vast majority of teratomas indeed do not show chromosomal aberrations on cytogenetic, CGH or array CGH analyses. ${ }^{13,16,17,47}$

Nevertheless, it is very important to note that two of the teratomas included in our study (and both immature central nervous system teratomas analyzed by Rickert et al) show chromosomal imbalances resembling those of malignant germ cell tumors. This might indicate that in contrast to teratomas in infants, teratomas of adolescents and adults might be related to a maturational differentiation of malignant germ cell tumors with a preservation of genetic aberrations that may result in a potentially malignant clinical presentation (accordingly, patient no. 3 showed tumor cell dissemination in the cerebrospinal fluid). In previous classification systems, this phenomenon had been attributed the term 'malignant teratoma, differentiated'. In accordance, we and other have found significant cytogenetic and CGH aberrations in residual or growing teratomas of patients with malignant nonseminomas (unpublished observation and van Echten et al ${ }^{56}$ ). Therefore, the histologic diagnosis of teratoma within the brain of a postpubertal patient should not result in confidence of benignity.

Considering these exceptions, 10 out of 14 malignant germ cell tumors of patients older than 5 years showed gain of $12 p$. The Figures 3 and 4 illustrate that this frequency is almost identical to that found in testicular ${ }^{11,34}$ and mediastinal germ cell tumors of adolescents and adults. ${ }^{17}$ In addition, our meta-analysis underlines that CNS-GCTs without $12 \mathrm{p}$ gain do not show chromosomal patterns distinct from other germ cell tumors.

\section{Restricted Amplification of 12p12}

We observed one patient whose tumor demonstrated a circumscribed amplification of 12p12. To date, comparable profiles have only been detected in testicular and ovarian (Riopel et al) germ cell tumors but not in extragonadal germ cell tumors. Albrecht et $a l^{57}$ published a cytogenetic analysis of a central nervous system germinoma that showed a homogeneously staining region (HSR), the chromosomal origin of which could not be identified by FISH with painting probes to the chromosomes 6 or 12 .

In testicular tumors, gain of chromosomal material at $12 p$ in the absence of an isochromosome $12 p$ is also related to the presence of either an HSR or double minutes. Microarray and FISH analyses helped to delineate the commonly amplified region at $12 \mathrm{p} 12$. It is generally assumed that the amplification of tumor genes at this region triggers malignant transformation at the transition from TIN to invasive malignant germ cell tumors. ${ }^{8,9,31}$ Since in our patient the amplicon is located at the identical chromosomal region as in testicular germ cell tumors, this observation provides additional evidence in favor of a common pathogenesis of testicular and CNS-GCTs.

In conclusion, this CGH data obtained in our present series of 19 CNS-GCTs and their comparison to previous findings in gonadal and extragonadal germ cell tumors clearly indicate that at the resolution level of CGH, CNS-GCTs are virtually indistinguishable from malignant germ cell tumors at other sites presenting in the same age group. This observation strongly argues for a similar genetic constitution and biology of germ cell tumors at different sites.

\section{Acknowledgements}

This study has been supported by a Max-Eder Grant of the German Cancer Aid (Deutsche Krebshilfe), the Children Cancer Foundation of Maryland and the American Cancer Society, Grant Number RPG-97113-01-CCE. We thank Dieter Harms for providing tissue samples, Amy E Schuster for technical assistance and Renate Groth and Susanne Koch for data management.

\section{Conflict of interest}

None.

\section{References}

1 Schneider DT, Calaminus G, Koch S, et al. Epidemiological analysis of 1442 children and adolescents registered in the german germ cell tumor protocols. Pediatr Blood Cancer 2004;42:169-175.

2 Calaminus G, Bamberg M, Baranzelli MC, et al. Intracranial germ cell tumors: a comprehensive update of the European data. Neuropediatrics 1994;25:26-32.

3 Calaminus G, Bamberg M, Harms D, et al. AFP/betaHCG secreting CNS germ cell tumors: long-term outcome with respect to initial symptoms and primary tumor resection. Results of the cooperative trial MAKEI 89. Neuropediatrics 2005;36:71-77. 
4 Bussey KJ, Lawce HJ, Himoe E, et al. SNRPN methylation patterns in germ cell tumors as a reflection of primordial germ cell development. Genes Chromosomes Cancer 2001;32:342-352.

5 Schneider DT, Schuster AE, Fritsch MK, et al. Multipoint imprinting analysis indicates a common precursor cell for gonadal and nongonadal pediatric germ cell tumors. Cancer Res 2001;61:7268-7276.

6 Sievers S, Alemazkour K, Zahn S, et al. IGF2/H19 imprinting analysis with the methylation-sensitive single nucleotide primer extension method in human germ cell tumors reflects their origin from different stages of primordial germ cell development. Genes Chromosomes Cancer 2005;44:256-264.

7 Oosterhuis JW, Looijenga LH. Testicular germ-cell tumours in a broader perspective. Nat Rev Cancer 2005;5:210-222.

8 Zafarana G, Gillis AJ, van Gurp RJ, et al. Coamplification of DAD-R, SOX5, and EKI1 in human testicular seminomas, with specific overexpression of DAD-R, correlates with reduced levels of apoptosis and earlier clinical manifestation. Cancer Res 2002;62: 1822-1831.

9 Zafarana G, Grygalewicz B, Gillis AJ, et al 12pAmplicon structure analysis in testicular germ cell tumors of adolescents and adults by array CGH. Oncogene 2003;22:7695-7701.

10 van Echten J, Oosterhuis JW, Looijenga LH, et al. No recurrent structural abnormalities apart from i(12p) in primary germ cell tumors of the adult testis. Genes Chromosomes Cancer 1995;14:133-144.

11 Korn WM, Oide Weghuis DE, Suijkerbuijk RF, et al. Detection of chromosomal DNA gains and losses in testicular germ cell tumors by comparative genomic hybridization. Genes Chromosomes Cancer 1996;17: 78-87.

12 Oosterhuis JW, Looijenga LH, van Echten J, et al. Chromosomal constitution and developmental potential of human germ cell tumors and teratomas. Cancer Genet Cytogenet 1997;95:96-102.

13 Bussey KJ, Lawce HJ, Olson SB, et al. Chromosome abnormalities of eighty-one pediatric germ cell tumors: sex- , age-, site-, and histopathology-related differences - a Children's Cancer Group study. Genes Chromosomes Cancer 1999;25:134-146.

14 Perlman EJ, Hu J, Ho D, et al. Genetic analysis of childhood endodermal sinus tumors by comparative genomic hybridization. J Pediatr Hematol Oncol 2000;22:100-105.

15 Mostert M, Rosenberg C, Stoop H, et al. Comparative genomic and in situ hybridization of germ cell tumors of the infantile testis. Lab Invest 2000;80: 1055-1064.

16 Veltman I, Veltman J, Janssen I, et al. Identification of recurrent chromosomal aberrations in germ cell tumors of neonates and infants using genomewide array-based comparative genomic hybridization. Genes Chromosomes Cancer 2005;43:367-376.

17 Schneider DT, Schuster AE, Fritsch MK, et al. Genetic analysis of mediastinal nonseminomatous germ cell tumors in children and adolescents. Genes Chromosomes Cancer 2002;34:115-125.

18 Rickert CH, Simon R, Bergmann M, et al. Comparative genomic hybridization in pineal germ cell tumors. J Neuropathol Exp Neurol 2000;59:815-821.
19 de Bruin TW, Slater RM, Defferrari R, et al. Isochromosome 12p-positive pineal germ cell tumor. Cancer Res 1994;54:1542-1544.

20 Losi L, Polito P, Hagemeijer A, et al. Intracranial germ cell tumour (embryonal carcinoma with teratoma) with complex karyotype including isochromosome 12p. Virchows Arch 1998;433:571-574.

21 Dal Cin P, Dei Tos AP, Qi H, et al. Immature teratoma of the pineal gland with isochromosome 12p. Acta Neuropathol (Berl) 1998;95:107-110.

22 Lemos JA, Barbieri-Neto J, Casartelli C. Primary intracranial germ cell tumors without an isochromosome 12p. Cancer Genet Cytogenet 1998;100:124-128.

23 Okada Y, Nishikawa R, Matsutani M, et al. Hypomethylated $\mathrm{X}$ chromosome gain and rare isochromosome $12 \mathrm{p}$ in diverse intracranial germ cell tumors. J Neuropathol Exp Neurol 2002;61:531-538.

24 Rickert CH, Simon R, Bergmann M, et al. Comparative genomic hybridization in pineal parenchymal tumors. Genes Chromosomes Cancer 2001;30:99-104.

25 Kleihues P, Burger PC, Scheithauer BW. The new WHO classification of brain tumours. Brain Pathol 1993;3: 255-268.

26 Mostofi FK, Sobin LH. Histopathological Typing of Testis Tumors. World Health Organization: Geneva, 1993.

27 Ausubel FM, Brent R, Kingston RE, et al. Preparation and analysis of DNA. In: Ausubel FM, Brent R, Kingston RE, Moore DD, Seidman JG, Smith JA, Struhl K (eds). Short Protocols in Molecular Biology. 3 edn. John Wiley \& Sons, Inc.: New York, 1997, pp 2-1-2-43.

28 Isola J, DeVries S, Chu L, et al. Analysis of changes in DNA sequence copy number by comparative genomic hybridization in archival paraffin-embedded tumor samples [see comments]. Am J Pathol 1994;145: 1301-1308.

29 Riopel MA, Spellerberg A, Griffin CA, et al. Genetic analysis of ovarian germ cell tumors by comparative genomic hybridization. Cancer Res 1998;58: 3105-3110.

30 Ness GO, Lybaek H, Houge G. Usefulness of highresolution comparative genomic hybridization (CGH) for detecting and characterizing constitutional chromosome abnormalities. Am J Med Genet 2002;113: 125-136.

31 Ottesen AM, Skakkebaek NE, Lundsteen C, et al. Highresolution comparative genomic hybridization detects extra chromosome arm 12p material in most cases of carcinoma in situ adjacent to overt germ cell tumors, but not before the invasive tumor development. Genes Chromosomes Cancer 2003;38:117-125.

32 du Manoir S, Schrock E, Bentz M, et al. Quantitative analysis of comparative genomic hybridization. Cytometry 1995;19:27-41.

33 Kirchhoff M, Rose H, Lundsteen C. High resolution comparative genomic hybridisation in clinical cytogenetics. J Med Genet 2001;38:740-744.

34 Mostert MM, van de PM, Olde WD, et al. Comparative genomic hybridization of germ cell tumors of the adult testis: confirmation of karyotypic findings and identification of a 12p-amplicon. Cancer Genet Cytogenet 1996;89:146-152.

35 Chibon F, Mariani O, Mairal A, et al. The use of clustering software for the classification of comparative genomic hybridization data. an analysis of 109 malignant fibrous histiocytomas. Cancer Genet Cytogenet 2003;141:75-78. 
36 Einhorn LH, Donohue JP. Chemotherapy for disseminated testicular cancer. Urol Clin North Am 1977;4: 407-426.

37 Bamberg M, Kortmann RD, Calaminus G, et al. Radiation therapy for intracranial germinoma: results of the German cooperative prospective trials MAKEI 83/86/89. J Clin Oncol 1999;17:2585-2592.

38 Bouffet E, Baranzelli MC, Patte C, et al. Combined treatment modality for intracranial germinomas: results of a multicentre SFOP experience. Societe Francaise d’Oncologie Pediatrique. Br J Cancer 1999; 79:1199-1204.

39 Balmaceda C, Finlay J. Current advances in the diagnosis and management of intracranial germ cell tumors. Curr Neurol Neurosci Rep 2004;4:253-262.

40 Kellie SJ, Boyce H, Dunkel IJ, et al. Primary chemotherapy for intracranial nongerminomatous germ cell tumors: results of the second international CNS germ cell study group protocol. J Clin Oncol 2004;22:846-853.

41 Calaminus G, Bamberg M, Jürgens $\mathrm{H}$, et al. Impact of surgery, chemotherapy and irradiation on long term outcome of intracranial malignant non-germinomatous germ cell tumors: results of the German Cooperative Trial MAKEI 89. Klin Pädiatr 2004;216:141-149.

42 Jong JD, Stoop H, Dohle GR, et al. Diagnostic value of OCT3/4 for pre-invasive and invasive testicular germ cell tumours. J Pathol 2005;206:242-249.

43 Stoop H, van Gurp R, de Krijger R, et al. Reactivity of germ cell maturation stage-specific markers in spermatocytic seminoma: diagnostic and etiological implications. Lab Invest 2001;81:919-928.

44 Looijenga LH, Stoop H, De Leeuw HP, et al. POU5F1 (OCT3/4) identifies cells with pluripotent potential in human germ cell tumors. Cancer Res 2003;63: 2244-2250.

45 Honecker F, Stoop H, de Krijger RR, et al. Pathobiological implications of the expression of markers of testicular carcinoma in situ by fetal germ cells. J Pathol 2004;203:849-857.

46 Schneider DT, Perlman EJ, Harms D, et al. Mediastinal germ cell tumors (MGCT) in children and adolescents: age correlates with histological differentiation, genetic profiles and clinical outcome. In: Harnden P, Joffe JK, Jones WG (eds). Germ Cell Tumours V. Springer: London, 2002, pp 127-128.

47 Schneider DT, Schuster AE, Fritsch MK, et al. Genetic analysis of childhood germ cell tumors with comparative genomic hybridization. Klin Pädiatr 2001;213: 204-211.

48 Hasle H, Mellemgaard A, Nielsen J, et al. Cancer incidence in men with Klinefelter syndrome. Br J Cancer 1995;71:416-420.

49 Nichols CR, Heerema NA, Palmer C, et al. Klinefelter's syndrome associated with mediastinal germ cell neoplasms. J Clin Oncol 1987;5:1290-1294.

50 Hashimoto M, Hatasa M, Shinoda S, et al. Medulla oblongata germinoma in association with Klinefelter syndrome. Surg Neurol 1992;37:384-387.

51 Casalone R, Righi R, Granata P, et al. Cerebral germ cell tumor and XXY karyotype. Cancer Genet Cytogenet 1994;74:25-29.

52 Prall JA, McGavran L, Greffe BS, et al. Intracranial malignant germ cell tumor and the Klinefelter syndrome. Case report and review of the literature. Pediatr Neurosurg 1995;23:219-224.

53 Yu IT, Griffin CA, Phillips PC, et al. Numerical sex chromosomal abnormalities in pineal teratomas by cytogenetic analysis and fluorescence in situ hybridization. Lab Invest 1995;72:419-423.

54 Garnis C, Coe BP, Lam SL, et al. High-resolution array $\mathrm{CGH}$ increases heterogeneity tolerance in the analysis of clinical samples. Genomics 2005;85:790-793.

55 Lau CC. Genomic profiling of intracranial germ cell tumors [abstract]. Neurooncol 2005;7:514-515.

56 van Echten J, Sleijfer DT, Wiersema J, et al. Cytogenetics of primary testicular nonseminoma, residual mature teratoma, and growing teratoma lesion in individual patients. Cancer Genet Cytogenet 1997;96:1-6.

57 Albrecht S, Armstrong DL, Mahoney DH, et al. Cytogenetic demonstration of gene amplification in a primary intracranial germ cell tumor. Genes Chromosomes Cancer 1993;6:61-63. 